\title{
HORMONAL MANIFESTATIONS OF THYROID CANCER ASSOCIATED WITH AUTOIMMUNE THYROIDITIS
}

\author{
Ina Sclifos 1 (iD)
}

${ }^{1}$ Public Health Institution Institute of Oncology, Chisinau, Rebublic of Moldova, Nicolae Testemitanu, University of Medicine and Pharmacy, Chisinau, Republic of Moldova

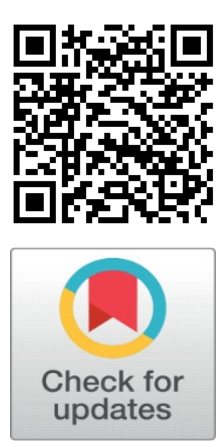

Received 25 September 2021

Accepted 18 October 2021

Published 31 October2021

\section{CorrespondingAuthor}

Ina Sclifos, sclifos.ina@yahoo.com

DOI

10.29121/granthaalayah.v9.i10.2021 .4291

Funding: This research received no specific grant from any funding agency in the public, commercial, or not-for-profit sectors.

Copyright: (C) 2021 The Author(s). This is an open access article distributed under the terms of the Creative Commons Attribution License, which permits unrestricted use, distribution, and reproduction in any medium, provided the original author and source are credited.

\section{ABSTRACT}

In medical practice, early diagnosis of CT is difficult because the neoplasm coexists or develops against the background of nodular-inflammatory thyroid pathologies, which have a slow evolution, CT is often associated with thyroiditis. The association of thyroid carcinoma with autoimmune thyroiditis remains debatable. In the literature, this combination is noted in $1 \%$ to $75 \%$ of cases. In recent years, there has been a steady increase in the number of thyroid cancers developed against the background of autoimmune thyroiditis, this being explained by improved diagnostic methods, living environment and increasing the number of elderly people. The relationship between inflammation and cancer is known to be that patients with autoimmune thyroiditis have a higher risk of developing thyroid cancer. The literature does not fully elucidate the hormonal peculiarities of thyroid cancer associated with autoimmune thyroiditis have not been studied yet in the Repulic of Moldova

Motivation: The hormonal peculiarities of thyroid cancer associated with autoimmune thyroiditis have not been studied yet in the Republic of Moldova.

Method: In order to analyze the hormonal manifestations, the patients were preoperatively collected tests for hormones from the venous blood.

Results: In thyroid cancer associated with autoimmune thyroiditis as well as patients in the control group have in most cases normal values of T3 and T4. The TSH value is within the norm in most patients included in the study in both the research group and the control group, and the increased value of the TSH index was observed more in patients with thyroid carcinoma associated with autoimmune thyroiditis. We conclude that thyroid cancer associated with autoimmune thyroiditis in most cases is accompanied by the increased antiTPO marker.

Conlusions: Thyroid cancer associated with autoimmune thyroiditis in most cases occurs with the increased antiTPO and TSH.

Keywords: Thyroid Cancer, Autoimmune Thyroiditis, Hormonal Manifestations

\section{INTRODUCTION}

In medical practice, early diagnosis of CT is difficult because the neoplasm coexists or develops against the background of nodular-inflammatory thyroid pathologies, which have a slow evolution, CT is often associated with thyroiditis. The association of thyroid carcinoma with autoimmune thyroiditis remains debatable. In the literature, this combination is noted in $1 \%$ to $75 \%$ of cases. In recent years, there has been a steady increase in the number of thyroid cancers developed against the background of autoimmune thyroiditis, this being explained by improved diagnostic methods, living environment and increasing the number of elderly people. The relationship between inflammation and 
cancer is known to be that patients with autoimmune thyroiditis have a higher risk of developing thyroid cancer. The literature does not fully elucidate the particularities of the diagnosis and treatment of thyroid cancer associated with lymphocytic thyroiditis (autoimmune).

\section{MATERIALS AND METHODS}

The research was conceived as a prospective, descriptive, comprehensive study and cohort observational analytical study. 234 patients were enrolled, who were treated in the scientific laboratory tumors of the head and neck region of the IMSP Oncological Institute. The study was conducted during the years 2017-2020 with the approval of the Research Ethics Committee of the State University of Medicine and Pharmacy "Nicolae Testemitanu" of the Republic of Moldova, minutes no. 76 from 14.11.2016. Patients met the criteria for inclusion in the study (consent of the patient with the signing of informed consent, age, patients with thyroid cancer developed on a healthy background and on the background of autoimmune thyroiditis).

The cases were divided into 2 groups, group 1 (research) was in turn divided into 2 groups:

1) a. RESEARCH LOT (thyroid carcinoma + autoimmune thyroiditis (FNAC +) 55 patients

b. CT + AT (FNAC -) 57 patients

2) Lot of control CT + HB (healthy background) 122 patients

All patients in group I group, a, underwent thyroid puncture (FNAC) of the thyroid nodules.

In order to analyze the hormonal manifestations, the patients were preoperatively collected tests for hormones from the venous blood.

The analysis of the data series was performed using the statistical applications of Microsoft Excel and the specialized software SofaStats ver. 1.4.6 (freeware). The data are presented in the form of absolute and relative values.

\section{RESULTS}

Thyroid hormone levels can be measured from blood samples and used to find out whether or not thyroid nodules are cancerous. Blood samples will also be checked for T3 and T4 (hormones that control metabolism). According to the literature, most thyroid cancers will have normal levels of T3 and T4.
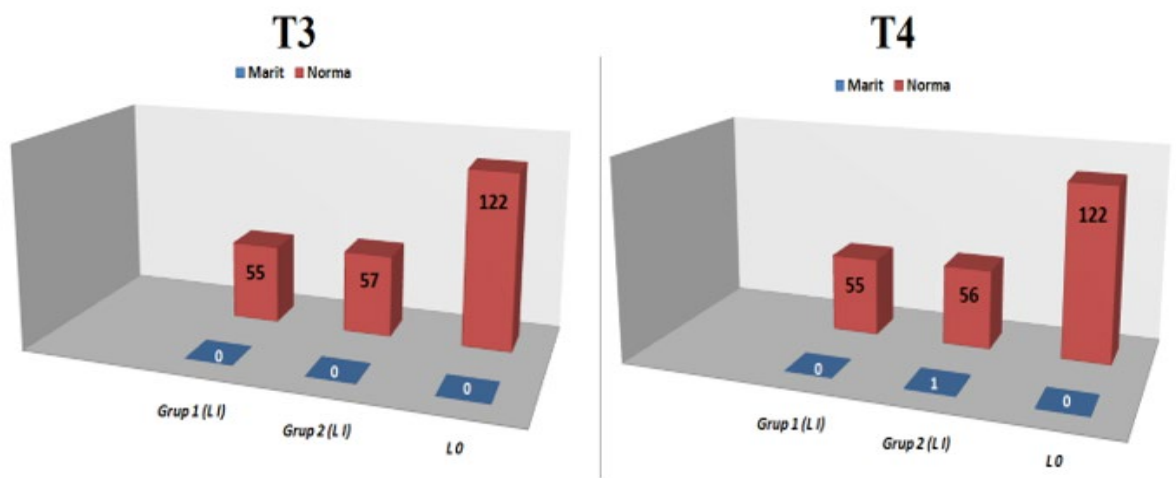

Figure 1 Distribution of patients depending on the value of T3 and T4

Note: Chi-score does not indicate a statistically significant difference (T4:3,101; $2 ; 0,212)$ 
Analyzing the figure above which illustrates the values of T3 hormone performed in patients, we notice that in both groups in the research group, including in the control group, there were no deviations from the norm. We observe the same results for the values of T4 hormone, which in the group 1 research group and in the control, group does not show any deviation from the norm, this being marked only in group 2 of the research group in 1 patient. Thus, we observe that in thyroid cancer associated with autoimmune thyroiditis as well as patients in the control group have in most cases normal values of T3 and T4. It is important to note that the lots did not show significant differences by the value of $\mathrm{T} 3$ and $\mathrm{T} 4$.

Nodular formations accompanied by suppressed TSH are generally considered without risk of malignancy. New data refer to the relationship between TSH levels and the risk of thyroid nodule malignancy and the practical consequences arising from it. There are studies that show that the risk of papillary cancer between thyroid nodules is directly proportional to the level of TSH. Baelaert (2009)

Table 1 Distribution of patients included in the study depending on the outcome of TSH

\begin{tabular}{|c|c|c|c|c|c|c|c|}
\hline & \multicolumn{4}{|c|}{$\begin{array}{l}\text { Research group (Lot I) } \\
\qquad \mathbf{n = 1 1 2}\end{array}$} & \multicolumn{2}{|c|}{$\begin{array}{l}\text { Lotul of control } \\
\qquad \begin{array}{l}\text { (Lot II) } \\
\mathbf{n}=122\end{array}\end{array}$} & \multirow{2}{*}{$\begin{array}{l}\text { Chi-scor } \\
\text { gl } \\
\text { p }\end{array}$} \\
\hline & \multicolumn{2}{|c|}{ Group 1} & \multicolumn{4}{|c|}{ Group 2} & \\
\hline & Abs. & $\%$ & Abs. & $\%$ & Abs. & $\%$ & \\
\hline smaller & - & - & 1 & 1,8 & 2 & 1,6 & 43,784 \\
\hline norm & 41 & $74,5^{*}$ & 37 & $64,9^{*}$ & 120 & $98,4^{*}$ & 4 \\
\hline bigger & 14 & 25,5 & 19 & 33,3 & - & - & 0,000 \\
\hline Total & 55 & 100 & 57 & 100 & 122 & 100 & \\
\hline \multicolumn{8}{|c|}{ Chi-score denotes a statistically significant difference, confirmed by the Fisher Exact test } \\
\hline
\end{tabular}

According to the data presented in Table 1 regarding the TSH value, we notice that in most patients the TSH value is normal, so in group 1 the TSH value was normal at (74.5\%) which represents 41 patients, and in group 2 it TSH value is normal at (64.9\%) which represents 37 patients. In the control group, the TSH value was normal at (98.4\%), which represents 120 patients. The TSH value in group 1 of the research group was increased to (25.5\%), which represents 14 patients, in group 2 of the same group the TSH value was increased to (33.3\%), which represents 19 patients, and in the group TSH control value was not increased in any patient. Thus, we conclude that the TSH value is within the norm in most patients included in the study in both the research group and the control group, and the increased value of the TSH index was observed more in patients with thyroid carcinoma associated with autoimmune thyroiditis.

The absolute risk for TSH patients normally in the research group is $39.6 \%$ (II: $32.8 \%-46.4 \%$ ), RR 0.431 (II: $0.354-0.525$ ), ie 0.431 of the risk presented by patients with high or low TSH. 
The distribution of patients depending on the antiTPO test showed a higher prevalence of this index in most patients in the research group, both groups, at the same time being normal in patients in the control group. (Table 2)

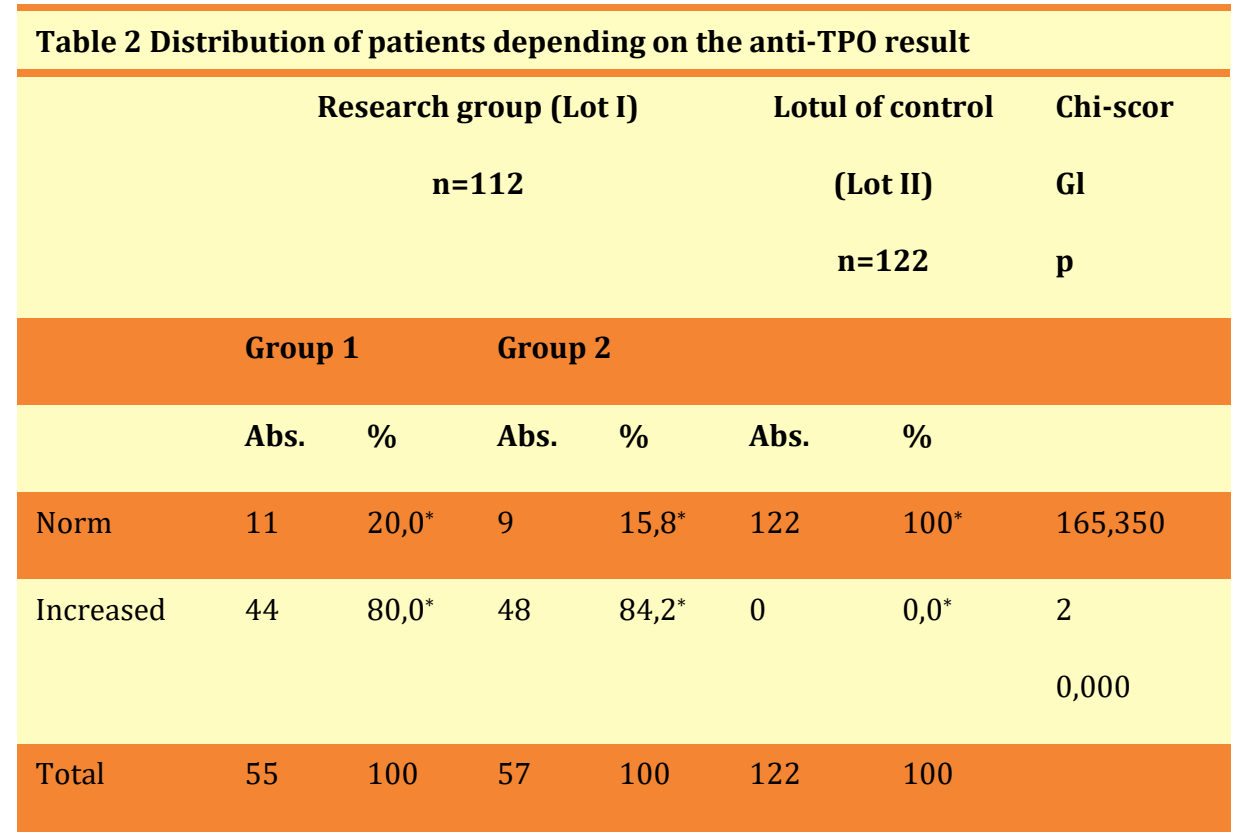

Chi-score denotes a statistically significant difference, confirmed by the Fisher Exact test

* difference compared to the control group

According to the data presented in Table 2, regarding the antiTPO value we observe a predominance in both groups from the research group of patients with increased antiTPO value, thus, in group 1 they constitute (80\%), which represents 44 patients, and in the group II of the research group they constituted (84.2\%), which represents 48 patients. No increase in antiTPO was recorded in any control group. Thus, we conclude that thyroid cancer associated with autoimmune thyroiditis in most cases is accompanied by the increased antiTPO marker.

The antiTG investigation was performed preoperatively because this marker may be a potential predictor of CT in patients with thyroid nodules and to assess whether there is an association of preoperative antiTG with the stage of the disease. Also, preToperated antiTG can be used postoperatively to assess the course of the disease and the occurrence of local recurrence or lymph node metastases. Boltze et al. (2002) The distribution of patients depending on the antiTG result is represented in Table 3.

A study by Ioannis Vasileiadis, Georgios Boutzios, Georgios Charitoudis, Eleni Koukoulioti, Theodore Karatzasa showed that antiTG positivity was an independent risk factor for CT. There was a positive correlation between antiTg and CT in patients with indeterminate nodules. In addition, there was a positive correlation between antiTg and lymph node metastases in patients with CT. Ioannis (2021) 


\begin{tabular}{|c|c|c|c|c|c|c|c|}
\hline & \multicolumn{4}{|c|}{$\begin{array}{l}\text { Research group (Lot I) } \\
\qquad n=112\end{array}$} & \multirow{2}{*}{\multicolumn{2}{|c|}{$\begin{array}{l}\text { Lotul of control } \\
\text { (Lot II) } \\
n=122\end{array}$}} & \multirow{4}{*}{$\begin{array}{l}\text { Chi-scor } \\
\text { gl } \\
\text { p }\end{array}$} \\
\hline & & & & & & & \\
\hline & \multicolumn{2}{|c|}{ Group 1} & \multicolumn{2}{|c|}{ Group 2} & & & \\
\hline & Abs. & $\%$ & Abs. & $\%$ & Abs. & $\%$ & \\
\hline Norm & 34 & $61,8^{*}$ & 34 & $59,6^{*}$ & 122 & $100^{*}$ & 59,114 \\
\hline Increased & 21 & $38,2^{*}$ & 23 & $40,4^{*}$ & 0 & $0,0^{*}$ & $\begin{array}{l}2 \\
0,000\end{array}$ \\
\hline Total & 55 & 100 & 57 & 100 & 122 & 100 & \\
\hline
\end{tabular}

Chi-score denotes a statistically significant difference, confirmed by the Fisher Exact test

* difference compared to the control group

According to the data presented in Table 3 regarding the antiTG value, we notice that in both groups from the patient research group, the increased antiTG value is registered, compared to the control group where this value is normal for all patients. Thus, in the group of research group 1 the increased antiTG value was at (38.2\%), which represents 21 patients, and in group II of the research group the antiTG value was increased to $(40.4 \%)$, which represents 23 patients. We mention the similarity of the norm for the antiTG value in the control group in no patient there was no increased value, situation identical to the increased antiTPO value.

\begin{tabular}{|c|c|c|c|c|c|c|c|}
\hline & \multicolumn{6}{|c|}{ AntiTG } & \multirow{2}{*}{$\begin{array}{l}\text { Chi-scor } \\
\text { gl p }\end{array}$} \\
\hline & \multicolumn{2}{|l|}{ Norm } & \multicolumn{2}{|c|}{ Increased } & \multicolumn{2}{|c|}{ TOTAL } & \\
\hline AntiTPO & Abs. & $\%$ & Abs. & $\%$ & Abs. & $\%$ & \\
\hline Norm & 17 & 25.0 & 3 & 6.8 & 20 & 17.9 & 6,021 \\
\hline Increased & 51 & 75.0 & 41 & 93.2 & 92 & 82.1 & $\begin{array}{l}1 \\
0,014\end{array}$ \\
\hline Total & 68 & 100 & 44 & 100 & 112 & 100 & \\
\hline
\end{tabular}

Chi-score denotes a statistically significant difference 
Cross tabulation of data on antiTPO and antiTG denotes that both hormones (antiTPO and antiTG) are increased in 41 patients, and increased antiTG and antiTPO normally only in 3 patients, thus, there is no cause-effect relationship between both indicators. increase thyroid cancer against the background of autoimmune thyroiditis.

\begin{tabular}{|c|c|c|c|c|c|c|c|}
\hline \multicolumn{7}{|c|}{$\begin{array}{c}\text { Table } 5 \text { Relationship betwee } \\
\text { AntiTG }\end{array}$} & \multirow{2}{*}{$\begin{array}{l}\text { Chi-scor } \\
\text { Gl p }\end{array}$} \\
\hline & Norm & & \multicolumn{2}{|c|}{ Increased } & \multicolumn{2}{|l|}{ TOTAL } & \\
\hline AntiTPO & Abs. & $\%$ & Abs. & $\%$ & Abs. & $\%$ & \\
\hline Norm & 122 & 100 & 0 & 0,0 & 122 & 100 & - \\
\hline Increased & 0 & 0,0 & 0 & 0,0 & 0 & 0,0 & \\
\hline Total & 122 & 100 & 0 & 0,0 & 112 & 100 & \\
\hline
\end{tabular}

Chi-score does not denote statistically significant difference

At the same time, we notice that the control group, which includes morphologically confirmed patients with thyroid cancer on a healthy background, antiTPO and antiTG are normal, so they cannot serve as paraclinical data that would objectify thyroid cancer.

\section{DISCUSSIONS}

The presence of chronic inflammation in autoimmune thyroiditis acting as an initiating factor in carcinogenesis, served as a potential explanation for the association between thyroid carcinoma and autoimmune thyroiditis. Subsequently, there have been various studies that have supported this association and others that have rejected it Imam et al. (2021), Dailey et al. (1955), Pino et al. (2021). The relationship between BP and CT is guided by the presence of thyroid antibodies and histopathological evidence of thyroiditis in cases of thyroid carcinoma. The seminal work of Fiore et al. on BP with CT showed high titers of thyroid antibodies compared to desinestant CT. The sustained inflammatory response in BP can act as a carcinogen. High levels of TSH found in patients with BP can stimulate follicular epithelial proliferation, thus promoting the development of thyroid carcinoma. Fiore et.aut. found that TSH levels also correlated more strongly with the presence of CT in nodular BP than in disintegrating nodular pathology with a probability ratio of 1,111 Fiore et al. (2004). McLeod et al. Watters et al. (2012) conducted a systemic review that included 5786 cases of thyroid cancer in 43,032 subjects and found that increased serum TSH gives a higher probability of developing thyroid cancer (probability ratio 1.87-2.83, depending on the level of TSH, a subgroup of studies that were adjusted for autoimmune thyroiditis did not find a similar relationship between TSH and the ratio of increased chances for thyroid cancer Bojana et al. (2013). The link between BP and thyroid cancer is still debated. Many plausible explanations for this observation could be that the type of immune response in patients who develop mild thyroid failure or remains euthyroid (with low or no TPO-Ab titer) may be different in comparison. with a population that becomes 
completely hypothyroid and with high anti-TPO titers.In addition, mild thyroid failure leads to slight increases in TSH levels. higher levels, but within normal limits, TSH values observed in these patients were associated with an increased risk of CT. Stimulation of thyroid cells by TSH activates the synthesis of thyroid hormone, including the activation of thyroid oxidases and the production of hydrogen peroxide, which is used in the organization of iodine. In patients with functional BP, stimulation of thyroid cells by TSH could be improved compared to non-functional thyroid. Therefore, exposure to higher concentrations of hydrogen peroxide and free radicals in the follicles could have DNA denaturing / mutagenic effects in thyroid cells and promote carcinogenesis. In patients with thyroid glands completely destroyed by autoimmunity, the absence of functional thyroid epithelium may not provide the substrate for TSH to act, thus reducing the risk of thyroid cancer compared to unaffected thyroid glands. All of these studies suggest a role for inflammation in the development of thyroid cancer. The absence or low titers of antiTPO in thyroid cancer patients is further evidence in support of the different nature of immune processes. Therefore, another possibility could be that we are dealing with two different processes that appear microscopically similar. In one, the autoimmune response is dominant, in the other the cancer seems to control immunity. We cannot rule out the possibility that thyroid cancer may be able to regulate the immune response in autoimmune thyroid disease. Further studies are needed to evaluate the types of immunity involved in various forms of BP and their effect on the development of thyroid cancer or vice versa Imam et al. (2021). The large variation in prevalence between studies is probably due not only to the different environmental and genetic factors involved, but especially to the various morphopathological definitions of BP.

\section{CONCLUSIONS}

There are no significant differences for T3 and T4, and the TSH value was within the norm in most patients included in the study, the increased value of the TSH index was observed mainly in patients with thyroid carcinoma associated with autoimmune thyroiditis. Thyroid cancer associated with autoimmune thyroiditis in most cases occurs with the increased antiTPO and antiTG marker. We mention the similarity of the norm for the antiTG value in the control group in no patient there was no increased value, situation identical to the increased antiTPO value.

\section{REFERENCES}

Baelaert K. (2009). The Association Between Serum Tsh And Tsh Concentration And Thyroid Cancer Endocrrelatcancer. 16(4): 1065-1072. Retrieved from https://doi.org/10.1677/ERC-09-0150

Bojana J, Et Al. (2013). Tiroidita Hashimoto Și Carcinomul Papilar Tiroidian: Există O Corelație? J Clin Endocrinol Metab. 98 : 474-482. Retrieved from https://doi.org/10.1210 / Jc.2012-2978

Boltze C, G Brabant, Dralle H, Gerlach R, Roessner A, Hoang Vu C. (2002). Radiație Indusă Carcinogenezei Tiroidian Ca Funcție De Timp Și De Aprovizionare Cu Iod Dietetice: Un Model In Vivo Al Tumorigeneza La Şobolan. Endocrinologie.143: 2584-92. Pubmed Google Academic. Retrieved from https://doi.org/10.1210/endo.143.7.8914

Dailey Me, Lindsay S, Skahen R. (1955). Relația Neoplasmelor Tiroidiene Cu Boala Hashimoto A Glandei Tiroide. Ama Arch. Surg. 70 : 291-297. Retrieved from https://doi.org/10.1001/archsurg.1955.01270080137023 
Fiore E. Et Al. (2004). Tiroidita Hashimoto Este Asociată Cu Carcinom Papilar Tiroidian: Rolul Tsh Și A Tratamentului Cu L-Tiroxină. Endocr Relat Cancer. 2011; 18 (4): 429-437. Retrieved from https://doi.org/10.1530/Erc-110028

Imam S, Paparodis R, Sharma D, Jaume Jc. . Endocr Relat Cancer 21 : 505-516 [ Articol Gratuit Pmc ]. Retrieved from https://doi.org/10.1530/ERC-130436

Imam S, Paparodis R, Sharma D, Jaume Jc. . Endocr Relat Cancer 21 : 505-516 [ Articol Gratuit Pmc ]. Retrieved from https://doi.org/10.1530/ERC-130436

Ioannis V. , Boutzios G., Charitoudis G., Koukoulioti E., Karatzas T. , Anticorpii Tiroglobulinici Ar Putea Fi Un Potențial Marker Predictive Pentru Carcinomul Tiroidian Papilar.

Pino Rivero V., Guerra Camacho M., Garcia M., Trinidad Ruiz G., Pardo Romero G, Gonzalez Palomino A, Blasco Huelva A. Incidența Carcinomului Tiroidian În Tiroidita Lui Hashimoto. Experiența Noastră Și Revizuirea Literaturii. Un Otorrinolaringol. Ibero. A.M. $31: 223-230$.

Watters Kf, Carpenter Ad, Ladenson Pw, Cooper Ds, Ding El. (2012) .Diagnosticul Diagnosticului Cu Tirotropină Și Cancer Tiroidian: $\mathrm{O}$ Analiză Sistematică Și O Meta-Analiză A Răspunsului La Doză-Răspuns. J Clin Endocrinol Metab. 97 : 2682-2692. Retrieved from https://doi.org/10.1210/jc.2012-1083 